\title{
IDENTIFICAÇÃO DE CROMO III COMO CONTAMINANTE EM GELATINAS COMERCIALIZADAS EM PRESIDENTE PRUDENTE-SP
}

\author{
Isabela Alves de Souza, Chelsea Pereira de Souza, Angélica Augusta Grigoli Dominato \\ Universidade do Oeste Paulista - UNOESTE, Curso de Biomedicina, Presidente Prudente, SP. e-mail: \\ angelica@unoeste.br
}

\section{RESUMO}

$\mathrm{O}$ cromo $\left(\mathrm{Cr}^{3+}\right)$ é necessário na dieta humana, principalmente para o metabolismo dos carboidratos. Pode ser encontrado em água potável, levedo de cerveja e grãos integrais, ou através de gelatinas contaminadas, proveniente da extração do colágeno no tratamento industrial do couro bovino, podendo causar danos à saúde quando ingerido acima de $200 \mu \mathrm{g} /$ dia. O objetivo deste trabalho foi investigar a presença de $\mathrm{Cr}^{3+} \mathrm{em}$ gelatinas comerciais de acordo com a legislação vigente. A metodologia utilizada foi análise por espectrofotometria de absorção atômica (EAA) após a digestão de oito amostras de gelatina, em triplicata (marcas do tipo colorida em pó, incolor em pó e em folha incolor). Os resultados obtidos demonstraram que todas as amostras de gelatina apresentaram concentrações de $\mathrm{Cr}^{+3}$ acima do permitido pela legislação $(0,1 \mathrm{ppm})$. Concluímos que $\mathrm{o} \mathrm{Cr}^{+3}$ pode ter sido arrastado durante o processamento do colágeno para a fabricação de gelatina e/ou adicionado ao produto colorido como corante.

Palavras-chave: cromo, gelatina, espectrofotometria por absorção atômica, colágeno e metais pesados.

\section{IDENTIFICATION OF CHROMIUM III AS CONTAMINANT IN GELATINS COMMERCIALIZED IN PRESIDENTE PRUDENTE-SP}

\begin{abstract}
The chromium $\left(\mathrm{Cr}^{+3}\right)$ is necessary in the human diet, mainly for the metabolism of carbohydrates. It can be found in drinking water, beer yeast and whole grains or through contaminated gelatins, derived from the extraction of collagen in the industrial treatment of bovine leather, and can cause damage to health when ingested above $200 \mu \mathrm{g} /$ day. The objective of this work was to investigate the presence of $\mathrm{Cr}^{+3}$ in commercial gelatins in accordance with current legislation. The methodology used was analyses by Atomic Absorption Spectrophotometry (AAS) after the digestion of eight gelatin samples in triplicate (colored powder type, colorless powder and colorless leaf). The results obtained showed that all gelatin samples presented concentrations of $\mathrm{Cr}^{+3}$ above that allowed by legislation $(0.1 \mathrm{ppm})$. We conclude that $\mathrm{Cr}^{+3}$ may have been entrained during the processing of collagen for the fabrication of gelatin and/or added to the colorful product as a colorant.
\end{abstract}

Keywords: chrome, gelatin, atomic absorption spectrophotometry, collagen e heavy metals.

\section{INTRODUÇÃO}

\section{Os elementos-traço, popularmente conhecidos como metais pesados, estão livremente distribuídos na natureza em baixas concentrações e podem apresentar algumas funções biológicas. Entretanto, em altas concentrações e determinadas formas oxidantes}

podem causar danos à saúde humana ${ }^{1}$. Entre esses elementos está o cromo que age no metabolismo dos carboidratos, lipídios e proteínas ${ }^{2}$.

O metal cromo $(\mathrm{Cr})$ apresenta três números de oxidação, $(+2),(+3)$ e $(+6)$, além da forma fundamental ${ }^{3}$. As propriedades 
nutricionais ou tóxicas são definidas conforme o estado de oxidação, entre eles os mais relevantes são o cromo III e VI ${ }^{4}$.

O cromo (III) é considerado um elemento necessário na dieta humana, devido à sua atividade nos metabolismos lipídico, proteico e principalmente de carboidratos, atuando na capacidade de interação da insulina com o aumento da captação de glicose pelas células ${ }^{5}$. Pode ser encontrado em água potável, levedo de cerveja e grãos integrais ${ }^{6}$. Para a manutenção das reações metabólicas, a Organização Mundial da Saúde (OMS) recomenda que a ingesta diária de $\mathrm{Cr}^{+3}$ para adultos esteja entre 50 a $200 \mu \mathrm{g}^{5}$. No entanto, em experimentos com animais demonstrou-se que a ingestão de $50 \mu \mathrm{g} \mathrm{de} \mathrm{Cr}^{+3}$ por grama de alimento consumido, desencadeia baixa no crescimento combinado de lesões hepáticas e renais ${ }^{2}$. O excesso pode desencadear reações alérgicas como vermelhidão e inchaço da pele em pessoas extremamente sensíveis a este metal ${ }^{7}$. A deficiência de $\mathrm{Cr}^{+3}$ pode causar neuropatia e encefalopatia ${ }^{8}$, já sua ausência no organismo gera alterações no metabolismo afetando a interação da insulina com o receptor celular, gerando intolerância à glicose ${ }^{2} \cdot \mathrm{O} \mathrm{Cr}^{3+}$ pode apresentar toxicidade ao organismo quando ingerido em dosagens muito superiores a 200 $\mu g^{5}$.

O cromo pode ser perigoso ao ambiente quando encontrado com o número de oxidação 6, passando a ser considerado tóxico, portanto é imprescindível o controle da circulação (transporte e transformação) do cromo assim como sua presença na atmosfera. ${ }^{5}$ Pode estar presente tanto nas atividades domésticas como industriais, sendo esta, alvo de constante estudo $^{9}$. Os usos mais comuns do cromo são mineração, indústria de cromagem e curtimento de couro ${ }^{9}$. O curtume ao cromo oferece características únicas ao couro como melhor resistência e capacidade de tingimento comparada aos outros produtos disponíveis no mercado em consonância com o baixo custo e preparação rápida ${ }^{10}$.

O colágeno, subtraído do couro bovino e suíno, é encaminhado para a indústria, onde após hidrolise parcial origina a gelatina. Este produto apresenta diferentes propriedades físicas e químicas devido às diferenças nos procedimentos de fabricação ${ }^{11}$.

Outras matérias-primas, além do couro bovino, são utilizadas para extrair o colágeno como os ossos de animais, porém no Brasil há elevada produção de carne para exportação, o que justifica a abundância da utilização de colágeno bovino $^{12}$.

Nos curtumes outros compostos são utilizados na manufatura do couro como o pentaclorofenol, formaldeído, fungicidas alergênicos e os metais pesados mercúrio, cádmio e zircônio ${ }^{13}$.

O procedimento para extração do colágeno é realizado em etapas: (1) o couro é cortado em pequenos pedaços ${ }^{14}$ e pré-tratado quimicamente para remoção de gordura e cálcio, promovendo uma desorganização estrutural do colágeno, antes de ser convertido em uma forma adequada para a extração; (2) início das extrações contínuas e os vários estágios de lavagem com água quente em temperaturas superiores a $45^{\circ} \mathrm{C}$; (3) etapa de desidratação da solução de gelatina em estufa seguida de filtração para obtenção de uma solução viscosa. A seguir, são geradas frações em formatos longos e cilíndricos (fibras), ou o colágeno em pó (triturado e posteriormente, estocado) ${ }^{13}$. Os restos das aparas de couro bovino, geradas após a fase de curtimento do couro, fornecem o colágeno para a gelatina após tratamento químico com formação de complexo de cromo III, com as cadeias laterais dos aminoácidos: ácido glutâmico e aspártico do colágeno ${ }^{15}$.

A formação do complexo cromocolágeno ocorre por interação entre a cadeia polipeptídica do colágeno com os sais básicos de cromo resultando em uma estrutura estável. A transferência da água intracelular para a matriz das fibras do colágeno acontece através do grupo carboxila, por meio de ligações covalentes. O cromo na forma de sulfeto oferece alcalinidade à reação, o que promove a difusão do sal e fixação do cromo na pele, evitando curtimento superficial $^{16}$ (Figura 1). 

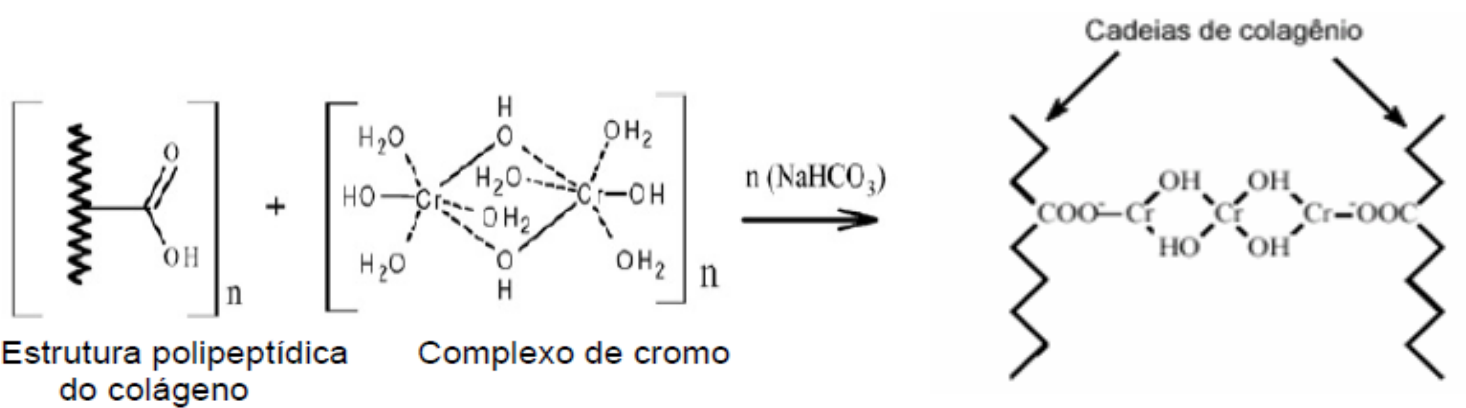

Figura 1. Esquema da formação do complexo cromo-colágeno no processo de curtimento de couros. Adaptado de Amaral $^{15}$, Castro ${ }^{16}$.

O colágeno é um produto utilizado nos setores industriais como alimentício, cosméticos e farmacêutico ${ }^{9}$. Com o intuito de estabelecer quantidades máximas de cromo nas gelatinas, a Consulta Pública no 55, de 18 de novembro de 2011, limitou em $0,1 \mathrm{mg} / \mathrm{kg}$ de cromo em gelatinas e produtos que contenham gelatina prontos para consumo ${ }^{18}$.

A produção brasileira de gelatina é realizada em larga escala, de baixo custo e com grande retorno financeiro ${ }^{17}$. Por isso a indústria alimentícia tem explorado a comercialização de gelatina, para todos os públicos. A importância do consumo de gelatina se justifica principalmente na fase adulta, já que é desenvolvida a deficiência de colágeno, pela diminuição da produção. Contudo, os alimentos que possuem colágeno em sua composição, incluindo a gelatina, melhoram a elasticidade e firmeza da pele e previnem doenças, como por exemplo a osteoartrite e osteoporose ${ }^{13}$.

Então, uma forma de consumo do colágeno está na gelatina comercializada com diferentes sabores e cores, muito apreciada pela população, principalmente por não possuir restrições e ser um alimento de grande apelo, especialmente para o público infantil, aliado ao preparo fácil ${ }^{9}$.

Por isso, o objetivo deste trabalho foi determinar a presença de $\mathrm{Cr}^{3+}$, como contaminante, em gelatinas comercializadas na cidade de Presidente Prudente (SP); quantificar o $\mathrm{Cr}^{3+}$ presente nas amostras de gelatinas; comparar as concentrações de $\mathrm{Cr}^{3+}$ presentes nas amostras, conforme a marca, sabor e cor; e comparar as concentrações encontradas com os valores permitidos pela legislação (ANVISA).

\section{METODOLOGIA}

Foram utilizadas oito amostras de gelatina, sendo cinco marcas do tipo colorida em pó, com sabor padronizado, duas incolores em pó e uma em folha incolor, todas em triplicata.

Todas as vidrarias utilizadas no procedimento foram previamente tratadas com solução de ácido nítrico $1: 1(\mathrm{v} / \mathrm{v})$ para a retirada de $\mathrm{Cr}$ como contaminante. O tratamento das amostras foi realizado por via úmida, através da hidrólise com ácido clorídrico (PA). 0 procedimento foi realizado dissolvendo a amostra, previamente em água Mili- $\mathrm{Q}^{\circledR}$, conforme a orientação do fabricante. Em seguida, as amostras foram transferidas para os tubos digestores e acrescentado $5,0 \mathrm{~mL}$ de ácido clorídrico 1:1 (v/v) nas amostras de gelatina colorida. Em cada gelatina incolor em pó foi acrescentado 7,5 $\mathrm{mL}$ do ácido clorídrico e 10,0 $\mathrm{mL}$ à amostra de gelatina incolor em folha. 0 frasco digestor foi mantido em chapa aquecedora a $100^{\circ} \mathrm{C} \pm 2^{\circ} \mathrm{C}$ coberto com vidro de relógio, sendo agitado ocasionalmente e mantido o refluxo por $2 \mathrm{~h}$, em capela de exaustão. A solução foi filtrada, ainda quente, para o balão volumétrico de $25 \mathrm{~mL}$ e o volume completado com água Mili- $Q^{\circledR}$. Antes de submeter às amostras digeridas ao EAA, as mesmas foram filtradas em papel de filtro qualitativo ${ }^{19}$.

A leitura das amostras foi realizada em espectrofotometria de absorção atômica (EAA) com o comprimento de onda $357,9 \mathrm{~nm}$ após a curva de calibração com o branco e as seguintes concentrações: 5,0 ppm, 10,0 ppm, 15,0 ppm, 20,0 ppm e 30,0 ppm.

As análises estatísticas foram realizadas utilizando o Programa R (versão 3.3.2) e seu pacote estatístico. 


\section{RESULTADOS}

Foram analisadas cinco marcas de gelatinas para as formas em pó, coloridas e com sabor, duas marcas para as formas em pó, incolor e sem sabor e apenas uma marca de gelatina no tipo em folha, incolor sem sabor.

As concentrações de cromo encontradas nas amostras estão demonstradas na Tabela 1.

Tabela 1. Concentração média de cromo trivalente $\left(\mathrm{Cr}^{+3}\right)$ nas amostras de gelatinas adquiridas no comércio de Presidente PrudenteSP.

\begin{tabular}{ccc}
\hline Marca & Espécie & $\begin{array}{c}\text { Concentr. média } \mathbf{C r}^{+3} \\
\text { ppm }\end{array}$ \\
\hline 1 & Pó, colorida & 1,4 \\
2 & Pó, colorida & 0,9 \\
3 & Pó, colorida & 1,4 \\
4 & Pó, colorida & 2,0 \\
5 & Pó, colorida & 1,5 \\
2 & Pó, Incolor & 1,7 \\
3 & Pó, Incolor & 2,0 \\
2 & Folha, incolor & 2,2 \\
\hline
\end{tabular}

Os resultados obtidos de concentração de cromo nas gelatinas incolores foram tratados estatisticamente com o teste $t$ para dados não paramétricos (Mann Whitney), pois só foram pesquisadas duas marcas. A análise demonstrou diferenças significativas entre as concentrações de cromo nas amostras incolores $(p<0,05)$. Nas amostras de gelatinas coloridas 0 teste estatístico utilizado foi Anova não paramétrico (Kruskal-Wallis), utilizado quando há mais de duas variáveis (marcas) a serem consideradas, seguido de teste de comparações múltiplas Dunn para analisar os pares específicos. A análise demonstrou diferenças significativas entre as concentrações de cromo nas amostras coloridas $(p<0,05)$. A respeito da marca 2 na espécie em folha, incolor e sem sabor não foi possível realizar análise estatística devido à falta de variedades de marcas no comércio.

Os resultados das análises estatísticas das amostras do tipo colorida e incolor estão apresentadas nas Figuras 2 e 3, respectivamente.

\section{Coloridas}

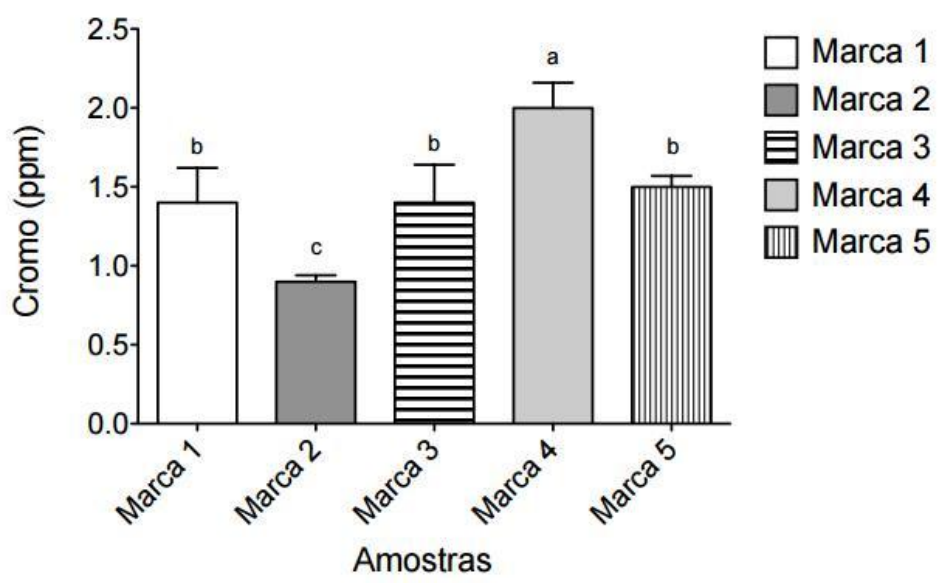

Figura 2. Cromo trivalente $\left(\mathrm{Cr}^{+3}\right)$ nas amostras de gelatinas coloridas adquiridas no comércio de Presidente Prudente-SP. 


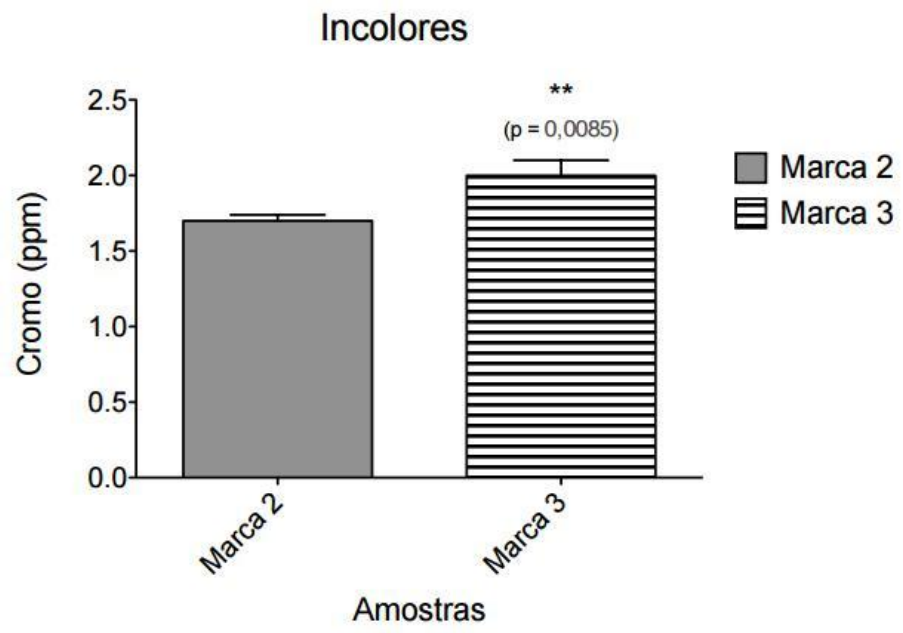

Figura 3. Cromo trivalente $\left(\mathrm{Cr}^{+3}\right)$ nas amostras de gelatinas incolores adquiridas no comércio de Presidente Prudente-SP.

Os resultados obtidos mostraram que todas as marcas de gelatina estudadas, independente do tipo, apresentaram $\mathrm{Cr}^{+3}$ na sua composição, e com valores acima do recomendado pela ANVISA ${ }^{16}$, com concentrações entre 0,9 a 2,2 ppm.

A marca 2 (gelatina em folha, incolor e sem sabor), apresentou a maior concentração de cromo dentre as gelatinas estudadas (2,2 ppm), seguida pela marca 3 (pó, incolor e sem sabor) e a marca 4 (pó, colorida e com sabor), com concentrações de 2,0 ppm. A marca 2 na espécie em pó, colorida com sabor padronizado de morango apresentou a menor concentração de cromo com 0,9 ppm.

A concentração de cromo na gelatina em pó e colorida, das marcas 1,3 e 5 apresentam resultados laboratoriais entre 0,9 a 2,0 ppm. As gelatinas incolores em pó, da marca 2 apresentou a concentração de cromo de 1,7 ppm e a marca 3 de $2,0 \mathrm{ppm}$.

\section{DISCUSSÃO}

A gelatina é um alimento fácil de digerir, popular entre as crianças e muito oferecido aos pacientes hospitalizados ${ }^{20}$. A ANVISA ${ }^{18}$ determina que a concentração máxima de cromo na gelatina deve ser menor que 0,1 ppm. Porém, todas as marcas analisadas continham quantidades de cromo até $22 x$ vezes maiores que o permitido. Se consumida por população imunocomprometida, crianças ou idosos pode causar mais danos à saúde ${ }^{20}$.

As altas concentrações de cromo trivalente presentes nas amostras poderiam ser atribuídas aos corantes adicionados às gelatinas coloridas. No entanto, amostras de gelatinas incolores apresentaram os valores mais elevados do que aquelas que continham corantes.

O colágeno utilizado para fabricação de todas as gelatinas analisadas nesta pesquisa é proveniente da indústria localizada em Presidente Epitácio (SP), cerca de $90 \mathrm{~km}$ de Presidente Prudente (SP). Foi constatado que as marcas 2 e 4 de gelatina colorida não apresentaram diferenças significativas com as demais marcas coloridas, logo associamos esse dado a possível discrepância no tratamento final de cada fábrica, responsável pelas marcas.

Para evitar a contaminação do colágeno extraído do couro curtido com $\mathrm{Cr}^{+3}$, é necessário o investimento em alternativas para o tratamento do couro. Algumas opções são hidrólise enzimática e ação bacteriana ${ }^{15}$; utilização dos resíduos como fonte nutritiva para plantas ${ }^{21}$ ou até mesmo o consumo de gelatinas cujo colágeno é obtido de outras fontes, como tarsos de frango ${ }^{17}$.

A carência na fiscalização pode ser um dos fatores que contribuem para encontrar concentrações acima dos valores permitidos pela legislação ${ }^{22}$.

O destino final dos resíduos de couro curtidos, contaminados por $\mathrm{Cr}^{+3}$, é outra preocupação da indústria, a fim de evitar sua oxidação para a forma que oferece maior risco de intoxicação o $\mathrm{Cr}^{+6}$. Freitas ${ }^{9}$ avaliou a água, onde os resíduos eram destinados, proveniente de dois curtumes no Mato Grosso do Sul, e determinou que a concentração de cromo atingiu níveis 
ecologicamente perigosos, apesar de não ter sido encontrado $\mathrm{Cr}^{+6}$ nos efluentes e corpos receptores.

$\mathrm{O} \mathrm{Cr}^{+6}$ apresenta características de substância carcinogênica, devido à facilidade de transpor membranas celulares, além da acumulação nos tecidos, ao longo do tempo ${ }^{23,24}$. No documento "A ANVISA na redução à exposição involuntária à fumaça do tabaco" da Agência Nacional de Vigilância Sanitária ${ }^{25}$ uma das substâncias encontradas na fumaça ambiental do tabaco (fumaça da ponta acesa + fumaça exalada pelo fumante) foi o cromo hexavalente, associado ao câncer de pulmão em humanos. Outras ações tóxicas descritas são perfuração do septo nasal, ulcerações, lesões renais ${ }^{5}$. As lesões podem atingir os sistemas, respiratório, gastrointestinal, além de mucosas e epitélio, conforme o tipo de exposição ${ }^{26}$. A toxicidade por cromo geralmente ocorre em ambiente industrial por inalação ou contato com a pele, mas a contaminação por resíduos na ingesta de gelatina também é possível ${ }^{5}$.

Conclui-se que todas as gelatinas adquiridas em supermercados estão com cromo acima do permitido pela legislação vigente. Este fato pode ter sido ocasionado pela ineficiência do tratamento para a retirada do cromo no processamento do couro e retirada do colágeno. A presença de cromo na gelatina incolor descarta a presença do metal nos corantes ou outros aditivos alimentícios.

\section{AGRADECIMENTOS}

Aos profissionais do laboratório de Análise de Alimentos e Análise de Solos na universidade pelo auxílio e execução de análises. À Universidade do Oeste Paulista (UNOESTE) pelo auxílio financeiro do Programa Especial de Iniciação Científica (PEIC) para realização desta pesquisa.

\section{CONFLITO DE INTERESSES}

Os autores declaram não haver qualquer potencial conflito de interesse que possa interferir na imparcialidade deste trabalho científico.

\section{REFERÊNCIAS}

1. Marchi G, Guilherme LRG, Silva CA, Gonçalves VC. Elementos-traço e sua relação com qualidade e inocuidade de fertilizantes, corretivos agrícolas e resíduos orgânicos no Brasil. Planaltina, DF: Embrapa
Cerrados, 2009. 45p. (Embrapa Cerrados. Documentos, 252).

2. Organização Mundial de Saúde. Elementos traço na nutrição e saúde humanas. 1.ed. São Paulo: Roca: WHO; 1998.

3. Borel JS, Anderson RA. Chromium. In: Frieden E. (Ed.). Biochemistry of the essential ultrace elements. New York: Plenum Press, 1984:175-99. DOI: https://doi.org/10.1007/978-1-4684-4775-0

4. Almodovar MLN. Estudo da anomalia de cromo nas águas subterrâneas da região noroeste do estado de São Paulo. [Dissertação]. São Paulo: Universidade de São Paulo, $1995 . \quad$ DOI: https://doi.org/10.11606/issn.2316-8986.v26i0p1-12

5. Gomes MR, Rogero MM, Tirapegui J. Considerações sobre cromo, insulina e exercício físico. Rev Bras Med Esporte 2005;11(5):262-6. DOI: https://doi.org/10.1590/S1517-86922005000500003

6. Pinheiro DM, Porto KRA, Menezes MES. A química dos alimentos: carboidratos, lipídeos, proteínas, vitaminas e minerais. Conversando sobre ciências em Alagoas. Maceió, AL: EDUFAL, 2005. 52p.

7. Anderson RA. Chromium. In: Smith KT (Ed.). Trace minerals in foods. New York: Marcel Dekker; 1988.

8. Gondal MA, Seddigi ZS, Nasr MM. et al. Spectroscopic detection of hazardous contaminants in lipstick using Laser Induced Breakdown Spectroscopy. Journal of Hazzardous Materials. 2010;175(1-3):72632.

DOI:

https://doi.org/10.1016/i.jhazmat.2009.10.069

9. Freitas TCM, Melnikov P. O uso e os impactos da reciclagem de cromo em indústrias de curtume em Mato Grosso do Sul, Brasil. Eng Sanit Ambient. 2006;11(4):305-10. DOI: https://doi.org/10.1590/S1413-41522006000400002

10. Abreu, MA. Reciclagem do resíduo de cromo da industria do curtume como pigmentos cerâmicos. [Tese]. São Paulo: Escola Politécnica da Universidade de São Paulo, 2006.

11. Roman JÁ, Sgarbieri VC. caracterização físicoquímica do isolado protéico de soro de leite e gelatina de origem bovina. Braz J Food Technol. 2007;10(2):137-43.

12. Silva, TF, Penna ALB. Colágeno: características químicas e propriedades funcionais. Rev Inst Adolfo Lutz. 2012;71(3):530-9. 
13. Souza RF. Investigação da presença de resíduo de pentaclorofenol em gelatina comestível por cromatografia a gás com captura de elétrons (CG/DCE). [Dissertação]. Porto Alegre: Instituto de Ciência e Tecnologia de Alimentos, Universidade Federal do Rio Grande do Sul, 2008.

14. Masilamani D, Madhan B, Shanmugam G, Palanivel $S$, Narayan B. Extraction of collagen from raw trimming wastes of tannery: a waste to wealth approach, J Cleaner Prod. 2015;113:338-44. DOI: https://doi.org/10.1016/j.jclepro.2015.11.087

15. Amaral LA. Alternativas para o tratamento de resíduos de couro curtido ao cromo - hidrólise enzimática e ação bacteriana. [Dissertação]. Porto Alegre: Departamento de Engenharia Química, Universidade Federal do Rio Grande do Sul, 2008.

16. Castro IA. Resíduo de couro "Wet Blue" após a extração do cromo: Uso como fertilizante nitrogenado em plantações de eucalipto. [Dissertação]. Minas Gerais: Universidade Federal de Lavras, 2011.

17. Almeida PF. Análise da qualidade de gelatina obtida de tarsos de frango e aspectos envolvidos no processo produtivo. [Dissertação]. São Paulo: Programa de Pós-Graduação em Engenharia de Produção da Universidade Nove de Julho, 2012.

18. Brasil. Ministério da Saúde. Agência Nacional de Vigilância Sanitária. Dispõe sobre os limites máximos toleráveis de cromo e cobre em alimentos e bebidas e dá outras providências. Brasília (DF): Ministério da Saúde; 2011. Acesso em 8 ago 2017. Disponível em: http://www.idec.org.br/uploads/audiencias documen tos/anexos/CP 55 2011.pdf

19. Instituto Adolfo Lutz. Métodos químicos e físicos para análises de alimentos. In: Sakuma AM, Kira CS, Maio FD, Okada IA, Buzzo ML, Duran MC et al. Normas Analíticas do Instituto Adolfo Lutz. São Paulo: São Paulo, 2005. p.735-54.

20. Schumann SPA, Polônio MLT, Gonçalves ECBA. Avaliação do consume de corantes artificiais por lactentes, pré-escolares e escolares. Ciênc Tecnol Alim. 2008;28(3):534-9. DOI: https://doi.org/10.1590/S0101-20612008000300005

21. Oliveira DQL, Carvalho KTG, Bastos ARR, Oliveira LCA, Marques JJGSM et al. Utilização de resíduos da indústria de couro como fonte nitrogenada para o capim-elefante. Rev Bras Ciênc Solo. 2008;32:417-24. DOI: https://doi.org/10.1590/S0100$\underline{06832008000100039}$

22. Silva TGN, Santos GR. Sistemas de gestão ambiental em curtumes. Rev Bras Gestão Amb.
2016;10(1):1-4.

DOi:

https://doi.org/10.24857/rgsa.v10i2.1226

23. Arruda MAS, Sussulini A. Determinação de cromo (VI) por espectrometria de absorção atômica com chama após a extração e pré-concentração no ponto nuvem. Eclét. Quím. 2006;31(1):73-80. DOI: https://doi.org/10.1590/S0100-46702006000100009

24. Fuck WF. Influência do teor de cromo e do tipo de óleo na formação do cromo hexavalente no couro. [Dissertação]. Universidade Federal do Rio Grande do Sul, Porto Alegre, 2008.

25. Gerência de Produtos Derivados do Tabaco GPDTA/ANVISA, A ANVISA na redução à exposição involuntária à fumaça do tabaco. In: Andrade ACB, Campelo, VRC. Agência Nacional de Vigilância Sanitária, 2009. p.1-24.

26. Costa LS, Pereira FRS, Farias, RF et al. Avaliação espectrofotométrica das formas $\mathrm{Cr}^{+3}, \mathrm{CrO}_{4}{ }^{-2}$ e $\mathrm{Cr}_{2} \mathrm{O}_{7}^{-2}$. Eclét. Quím. 2010;35(3):157-67. DOI: https://doi.org/10.1590/S0100-46702010000300016 